\title{
Disseminated leishmaniasis: clinical, pathogenic, and therapeutic aspects*
}

\author{
Gustavo Uzêda Machadoํㅜ, Fernanda Ventin Prates², Paulo Roberto Lima Machado²
}

DOI: http:/ / dx.doi.org/10.1590/abd1806-4841.20198775

\begin{abstract}
Disseminated leishmaniasis is a severe and emerging form of American tegumentary leishmaniasis. Disseminated leishmaniasis is defined by the presence of more than 10 polymorphic cutaneous lesions, distributed over more than two noncontiguous parts of the body. Nasal mucosal involvement is observed in almost half of cases. Disseminated leishmaniasis patients present with a decreased production of Th1 cytokines in the peripheral blood due to the attraction of leishmaniaactivated T cells to the multiple cutaneous lesions. Disseminated leishmaniasis development is poorly understood and is related to a complex network involving environmental, host immune response, and parasite factors, in which L. braziliensis polymorphism plays an important role. Disseminated leishmaniasis is a challenging disease to cure, presenting a high failure rate of $75 \%$ to pentavalent antimony therapy. Despite its importance and severity, this form of American tegumentary leishmaniasis has been poorly studied and documented, deserving greater attention from professionals working in endemic areas.
\end{abstract}

Keywords: Amphotericin B; Leishmania braziliensis; Leishmaniasis, cutaneous

\section{INTRODUCTION}

The leishmaniases make up a heterogeneous group of diseases caused by protozoans of the genus Leishmania. The disease affects about 2 million people per year. It is considered by the WHO as one of the six priority neglected tropical diseases. Tegumentary leishmaniasis is the most common form, affecting about 1 million people annually, mainly in association with poverty in developing countries. ${ }^{1}$ American tegumentary leishmaniasis (ATL) presents several different clinical forms depending on the interaction between host immune response, species, and genetic variability of Leishmania, as well as environmental factors. The main forms of ATL are cutaneous leishmaniasis (CL), mucosal leishmaniasis (ML), diffuse (anergic) cutaneous leishmaniasis (DCL), and disseminated leishmaniasis (DL). ${ }^{1,2}$

DL is characterized by the appearance of dozens to hundreds or thousands of polymorphic skin lesions in various body regions, and frequent involvement of the nasal mucosa. ${ }^{3,4}$ Although several protozoan parasites of the Leishmania genus causing ATL may be etiological agents of DL, most of the cases documented in the Americas are caused by Leishmania (Viannia) braziliensis. It is important to distinguish LD from the anergic diffuse form - a very rare

Received 10 September 2018.

Accepted 11 November 2018.

* Work conducted at the Immunology Service, Hospital Universitário Prof. Edgar Santos, Universidade Federal da Bahia, Salvador (BA), Brazil.

Financial support: None.

Conflict of interest: None.

Dermatology Service, Escola Bahiana de Medicina e Saúde Pública, Salvador (BA), Brazil.

2 Immunology Service, Hospital Universitário Prof. Edgar Santos, Universidade Federal da Bahia, Salvador (BA), Brazil.

MaILING Address:

Paulo Roberto Lima Machado

E-mail: prlmachado@uol.com.br 
form of ATL caused by L. amazonenses, a parasite commonly found in northern Brazil - and from atypical manifestations of ATL in immunosuppressed patients who have multiple cutaneous lesions.

In recent decades, a significant increase in the incidence of DL has been observed in northeastern Brazil. ${ }^{5}$ This is a worrying factor due to the aggressiveness of this little studied and little known form of leishmaniasis. Because it is an endemic long-term and difficult-to-treat disease, DL is considered a serious public health problem in neglected populations.

\section{EPIDEMIOLOGY}

Disseminated leishmaniasis was described in the state of Bahia by Torres in 1920, ${ }^{6}$ and was initially studied in relation to its clinical and immunological aspects in an endemic region of Northeast Brazil by Carvalho et al. ${ }^{3}$ DL has also been documented in other regions of Brazil and South America, as well as in Europe and in the Middle East. ${ }^{7-11}$

The endemic area of Corte de Pedra in the south of Bahia is a region of transmission of L. braziliensis, with diverse clinical presentations such as classical and localized ulcerated cutaneous leishmaniasis, mucosal leishmaniasis, atypical leishmaniasis, and disseminated leishmaniasis., ${ }^{5,12,13}$ Periodic epidemiological data show that the frequency of DL cases in Corte de Pedra has increased significantly and progressively. In the period between 1978 and 1984, DL was uncommon, accounting for only $0.2 \%$ of ATL cases in that region. ${ }^{12}$ Subsequently, a rapid increase in the frequency of DL cases was reported. Its incidence rate increased from $1.9 \%$ between $1992-1998^{4}$ to $3.9 \%$ between $2004-2008,{ }^{5}$ characterizing DL as an emerging infectious disease. The main risk factors associated with the development of DL in comparison to localized cutaneous leishmaniasis include male sex, age under 19 years, and agricultural occupations. ${ }^{4}$

\section{PATHOGENESIS}

\section{Parasitic factors}

The protozoan Leishmania is an obligate intracellular parasite mainly of macrophages, transmitted from animals to humans by several species of sandflies, especially of the genus Lutzomyia in Brazil. ${ }^{14}$ Although DL can be caused by more than one species of Leishmania, such as L. guyanensis and L. panamensis, in the Americas, L. braziliensis is the main cause of the disease. ${ }^{4,7-10}$ An interesting finding in the study conducted by Queiroz et al. ${ }^{15}$ in the region of Corte de Pedra is that L. braziliensis has a multiclonal population structure, in which different genotypes are associated with different clinical manifestations, including the disseminated form of the disease. In their study, a strong association between DL and specific strains of L. (V.) braziliensis was documented, suggesting that genetically distinct strains of the parasite may be responsible for the emergence of this form of ATL in several areas of the region. Therefore, the use of molecular markers may help track the spread of the disease. ${ }^{15}$

\section{IMMUNOLOGICAL FACTORS}

After the cutaneous inoculation of the flagellated forms (promastigote) of Leishmania, neutrophils and macrophages phagocytose the parasite that differentiates into a round aflagellated amastigote form. Local production of TNF- $\alpha$ and IL-12 drives the immune response to the secretion of Th1 cytokines such as IFN- $\gamma$ and others, which activate the macrophage to kill Leishmania. ${ }^{2}$ This defense mechanism is fundamental in the early stage of infection to prevent disease or to prevent the dissemination of the protozoan. However, the development of DL is often not directly related to host immunosuppression, since DL has been described in young and immunocompetent patients living in endemic areas. ${ }^{4,5}$

Although L. braziliensis antigens isolated from DL patients stimulate higher production of IFN $\gamma$ and TNF $\alpha$ than L. braziliensis antigens from CL patients, patients with DL have lower production of IFN $\gamma$ and TNF $\alpha$ by cells of peripheral blood when compared to individuals with CL. ${ }^{41,6}$ These findings suggest that a peripheral decrease in Th1 response allows for the spread of the parasite. Interestingly, in contrast to DCL and CL with multiple lesions in immunosuppressed patients - which are associated with high in situ parasite load - Leishmania amastigotes are not easily found in DL lesions and the Th1 response against Leishmania antigens is preserved in DL. ${ }^{3,16-19}$ In situ immune response in DL is characterized by IFN $\gamma$, TNF $\alpha$, CCL2, CCL3, CCL11, and CXCL10 expression in much the same way as in localized CL, whereas CXCL9 is produced in greater quantity by peripheral blood mononuclear cells from patients with DL compared to patients with CL. ${ }^{20}$ CXCL9 is an IFN $\gamma$-induced chemokine associated with recruitment and proliferation of T lymphocytes. ${ }^{21}$ These data suggest that a decrease in Th1 response in the peripheral blood of patients with DL is due to the attraction of Leishmania-specific T cells towards multiple cutaneous lesions. Therefore, the preserved tissue immune response in DL may explain the absence or low number of parasites in the lesions, as well as the development of ulcers similar to those observed in CL.

\section{CLINICAL MANIFESTATIONS}

In DL, the eruption and spread event occurs about 2-6 weeks after the initial ulcerated lesion. Several patients report systemic symptoms during this period, most commonly fever, asthenia, chills, malaise, and nausea, suggesting a process of parasitic dissemination, preferentially via the hematogenous route. ${ }^{3,4}$

The characteristic clinical picture of DL consists of the coexistence of several types of cutaneous lesions: acneiform eruptions, inflammatory papules (that may be eroded and crusted), nodules and ulcers, and rarely verrucous or vegetative lesions. Clinical manifestations can be varied, with at least 10 lesions in at least two noncontiguous body segments. Some patients can have up to hundreds or even thousands of lesions without sparing any body segment and showing mucous membrane invasion., The lesions may be exuberant on the face, but also strongly affect the trunk and limbs (Figures 1-5). Typical ulcerated lesions on the lower or upper limbs are common, with dissemination occurring in days or weeks (Figure 5). Mucosal involvement is frequent, which has been documented in up to $53 \%$ of cases, with a predilection for the nasal mucosa and often characterized by the presence of superficial inflammation without ulceration. A minority of cases may reveal a more intense involvement, with infiltration and ulceration of the nasal septum. ${ }^{22}$ The presence of lymphadenopathy in various body regions may occur during the dissemination phase in some patients. 


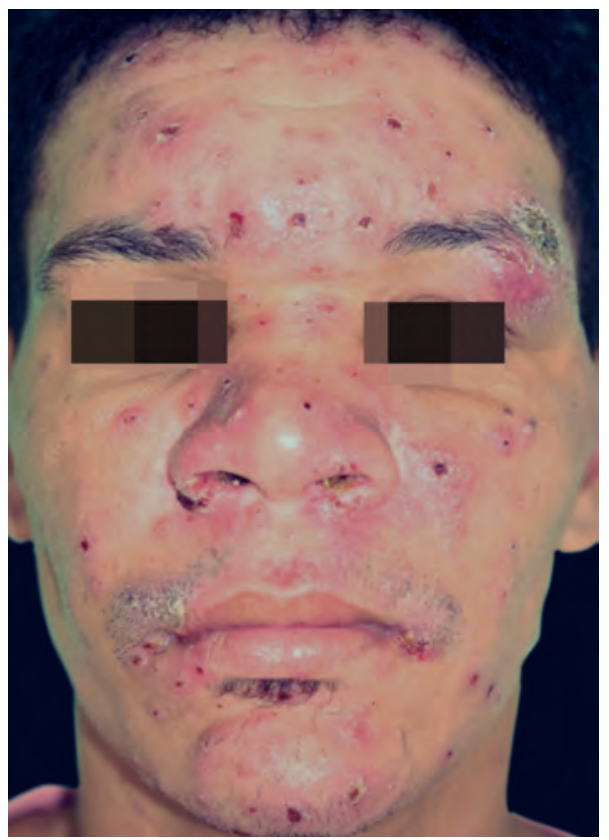

Figure 1:

Disseminated

Leishmaniasis 1

Exuberant crus-

ted papules and

inflammatory

nodules. Intense

facial involve-

ment. Agent: L.

(V.) braziliensis

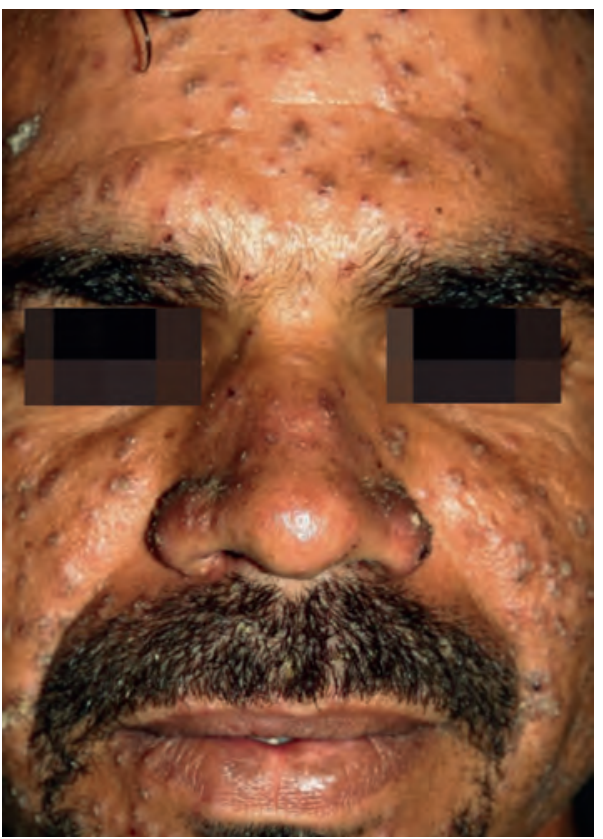

Figure 2:

Disseminated

Leishmaniasis

2. High number

of acneiform

lesions on the

face. Agent: L.

(V.) braziliensis

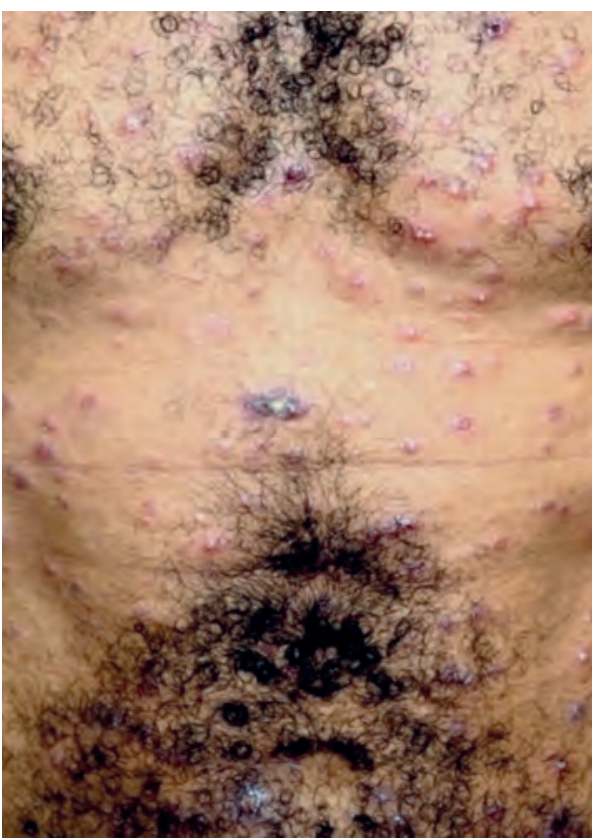

Figure 3:

Disseminated

Leishmanisis 3.

Acneiform and papulous lesions on the trunk. Agent: L. (V.) braziliensis

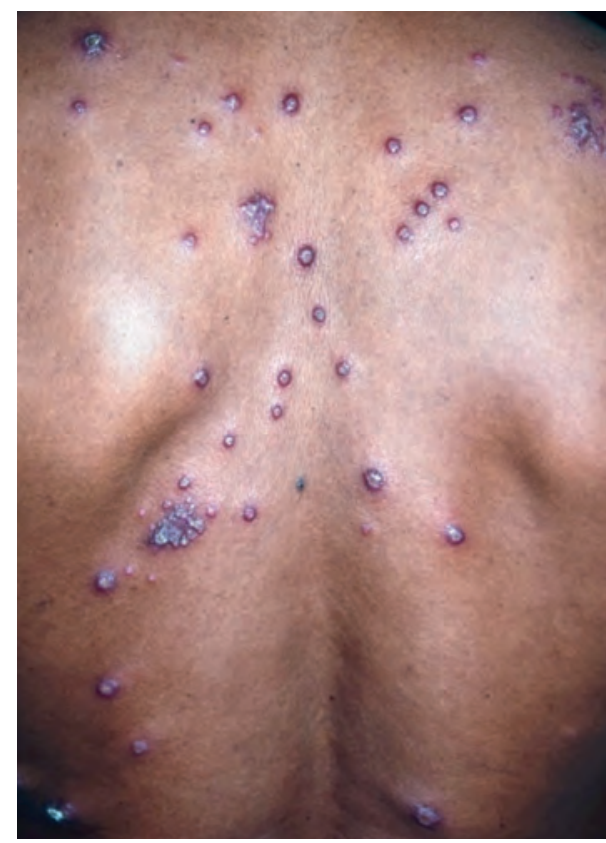

Figure 4:

Disseminated Leishmaniasis 4. Dozens of inflammatory erythemato violaceous papules with different sizes on the dorsal region. Etiologic agent: L. (V.)

braziliensis
The main differential diagnoses of DL are with other forms of ATL: diffuse (anergic) cutaneous leishmaniasis (DCL) and CL with multiple lesions in immunosuppressed patients. In the case of DCL, the clinical picture resembles some manifestations of lepromatous leprosy, such as infiltrated plaques and nodules. DL, in turn, predominantly exhibits superficial papular and inflammatory lesions, in addition to ulcerations. Table 1 shows the main differential elements between DL and DCL. In the case of CL with multiple lesions in immunosuppressed patients, no dissemination phase with systemic symptoms or polymorphism of cutaneous lesions - which are often atypical - has been reported. Moreover, Montenegro test is generally negative and the lesions exhibit a large number of amastigotes in the infiltrate. ${ }^{18,19}$ 


\section{LABORATORY DIAGNOSIS}

The diagnosis of DL is based on the clinical characteristics already described. Laboratory confirmation is based on Montenegro test, histopathological examination, and identification of the parasi-

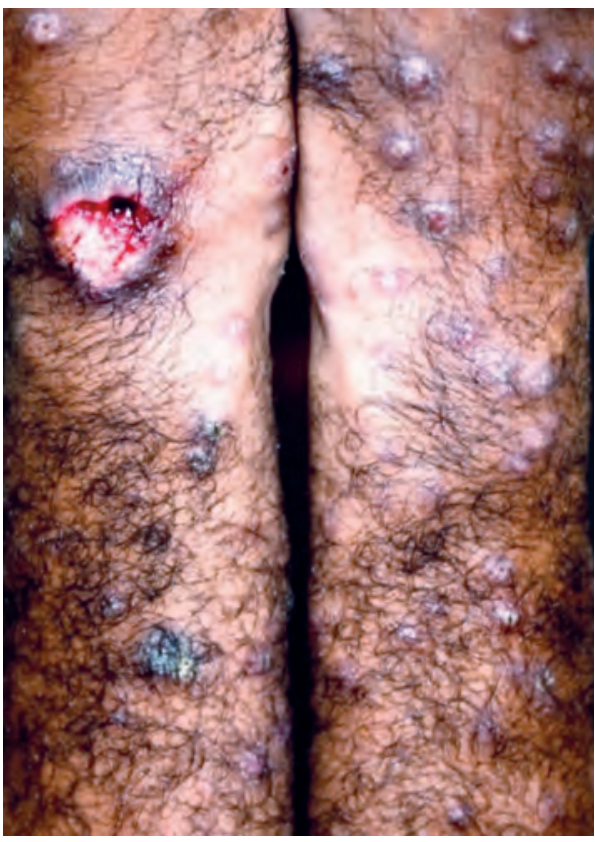

FIGURE 5:

Disseminated

Leishmaniasis 5.

Initial ulcerated

lesion and seve-

ral erithematous

papules after

dissemination.

Agent: L. (V.)

braziliensis

TABLE 1: Differential Diagnosis between disseminated leishmaniasis (DL) and diffuse (anergic) cutaneous leishmaniasis (DCL)

Disseminated leishmaniasis (DL)

Diffuse (anergic) cutaneous leishmaniasis (DCL)

\begin{tabular}{|c|c|c|}
\hline $\begin{array}{l}\text { Clinical } \\
\text { manifestations }\end{array}$ & $\begin{array}{l}\text { Acneiform papules, } \\
\text { inflammatory } \\
\text { papules, superficial } \\
\text { nodules; ulcers; } \\
\text { involvement of the } \\
\text { nasal mucosa by } \\
\text { up to } 53 \%\end{array}$ & $\begin{array}{l}\text { Infiltrated pla- } \\
\text { tes and nodules; } \\
\text { absence of ulcers; } \\
\text { absence of mucosal } \\
\text { involvement }\end{array}$ \\
\hline Montenegro Test & $\begin{array}{l}\text { Positive in up to } \\
83 \%\end{array}$ & Always negative \\
\hline Histopathology & $\begin{array}{l}\text { Absence or small } \\
\text { amount of para- } \\
\text { sites }\end{array}$ & $\begin{array}{l}\text { Presence of large } \\
\text { amount of amasti- } \\
\text { gotes in the dermal } \\
\text { infiltrate }\end{array}$ \\
\hline $\begin{array}{l}\text { (New world) } \\
\text { Leishmania } \\
\text { Species }\end{array}$ & $\begin{array}{l}\text { Mainly L.(V.) } \\
\text { braziliensis }\end{array}$ & L. amazonensis \\
\hline $\begin{array}{l}\text { Leishmania IFN } \\
\text { and TNF produc- } \\
\text { tion after stimu- } \\
\text { lation of periphe- } \\
\text { ral blood cells } \\
\text { with Leishmania } \\
\text { antigen }\end{array}$ & Present & Absent \\
\hline
\end{tabular}

te by culture or PCR. Montenegro test is positive in up to $83 \%$ of DL cases ${ }^{20}$ but negative in the diffuse (anergic) form ${ }^{17}$ and in immunosuppressed patients. ${ }^{18,19}$ Histopathology shows a mononuclear infiltrate with the presence of plasma cells. A granulomatous reaction may also be revealed. Histopathological examination also shows a few amastigote forms in the ulcerated lesions and intense perifollicular inflammation in the acneiform lesions. ${ }^{3}$ In DCL, however, the dermal cellular infiltrate shows a large quantity of amastigotes. A more recent study of papular and non-ulcerated lesions in DL shows lymphoplasmocytic infiltration in richly vascularized areas, with vasculitis and necrosis in some cases, in addition to granuloma, giant cells, and rare neutrophils. The predominant cell types were CD68+ cells (macrophages), CD20+ (B lymphocytes), and CD4+ (T lymphocytes). ${ }^{23}$

\section{TREATMENT}

DL is a difficult-to-treat disease due to the high number of lesions, frequent occurrence of mucosal involvement, and low cure rate of around $23 \%$ even at the maximum dose of $20 \mathrm{mg} \mathrm{SbV} / \mathrm{kg} /$ day for 30 days with pentavalent antimonial. ${ }^{4,20} \mathrm{SbV}$, marketed as Glucantime ${ }^{\circledR}$ in Brazil, is still the first-choice therapy despite its high toxicity, need for parenteral administration, long duration (2-3 months) for ulcer healing and lesions regression, and high risk of therapeutic failure. Its side effects include cardiotoxicity, pancreatitis, hepatic alterations, myalgia, and arthralgia. ${ }^{14,24}$ The vast majority of patients with DL require more than one course of treatment with $\mathrm{SbV}$ or prolonged use of high doses of amphotericin B deoxycholate for cure, which can take several months to be achieved. All these factors increase the impact of the disease, with significant socio-economic repercussions on a low-income population with few resources. $2,4,22$

In this context, liposomal amphotericin B may appear as a relevant therapeutic option for DL. Patients with CL by L. guyanensis, L. braziliensis, L. infantum or L. aethiopica have been treated with liposomal amphotericin B, which resulted in lower toxicity, shorter duration of treatment, and higher cure rates, around $80-90 \% .{ }^{25-27}$ In Brazil, an open-label clinical trial of 20 patients with DL caused by L. braziliensis showed a cure rate of $65 \%$ after treatment with liposomal amphotericin B at a cumulative total dose between $17 \mathrm{mg} /$ $\mathrm{kg}$ and $37 \mathrm{mg} / \mathrm{kg}$ over a period of 7-14 days. A cure rate above $75 \%$ was achieved when the total dose exceeded $30 \mathrm{mg} / \mathrm{kg}$. Although liposomal amphotericin B was well tolerated, mild side effects were documented in $75 \%$ of patients..$^{22}$ Recently, the Ministry of Health of Brazil has recommended the use of liposomal amphotericin B as the first-choice drug for the treatment of DL in patients over 50 years of age, patients with renal, cardiac, or hepatic insufficiency regardless of age, and pregnant women of any age. ${ }^{14}$ The recommended protocol is $2-3 \mathrm{mg} / \mathrm{kg} /$ day by venous infusion in a single daily dose until the total dose reaches $35-40 \mathrm{mg} / \mathrm{kg}$. In the case of impossibility of the use of liposomal amphotericin $\mathrm{B}, \mathrm{SbV}$ should be used (if there are no contraindications) at a dose of $20 \mathrm{mg} / \mathrm{kg} /$ day for 30 days, with a maximum of 3 ampoules per day. ${ }^{14}$

One option for future use may be miltefosine (MF), an oral drug that interacts with intracellular signaling pathways and inhibits phospholipid and sterol biosynthesis. ${ }^{28}$ It was the first oral drug 
approved for the treatment of visceral leishmaniasis in India, and has been used since 2002. ${ }^{29}$ Several studies have evaluated the efficacy of MF in the treatment of $\mathrm{CL}$, with results that vary according to the Leishmania species and the geographic region of the study. ${ }^{30-33}$ Unfortunately, MF is still not available in Brazil, despite its proven efficacy and safety in the treatment of CL caused by L. braziliensis (75\% cure) and L. guyanensis (71\% cure), the two most prevalent species in the country. ${ }^{32,33}$ Thus, although there are only a few case reports of DL patients treated successfully with MF alone or in com- bination with liposomal amphotericin, MF is likely to be a new therapy option for DL. ${ }^{34,35}$

Considering the therapeutic difficulty in DL cases, an important perspective is the use of associations to increase the efficacy of treatments, as observed in leprosy and tuberculosis treatment, in which the combination of drugs with antiparasitic activity can increase the rate of cure, decrease treatment resistance, and reduce toxicity by using lower doses of each drug. $]$

\section{REFERENCES}

1. Burza S, Croft SL, Boelaert M. Leishmaniasis. Lancet. 2018;392:951-970.

2. Rosa MEA, Machado PRL. Disseminated Leishmaniasis: Clinical, Immunological and Therapeutic Aspects. Drug Development Research. 2011;72:437-41.

3. Carvalho EM, Barral A, Costa JM, Bittencourt A, Marsden P. Clinical and immunopathological aspects of disseminated cutaneous leishmaniasis. Acta Trop. 1994:56:315-25

4. Turetz ML, Machado PR, Ko Al, Alves F, Bittencourt A, Almeida RP, et al. Disseminated Leishmaniasis: a new and emerging form of leishmaniasis observed in northeastern Brazil. J Infect Dis. 2002;186:1829-34

5. Jirmanus L, Glesby MJ, Guimarães LH, Lago E, Rosa ME, Machado PR, et al. Epidemiological and clinical changes in American tegumentary leishmaniasis in an area of Leishmania (Viannia) braziliensis transmission over a 20-year period. Am J Trop Med Hyg. 2012:86:426-33

6. Torres 0. A leishmaniose na Bahia. Arq Bras Med. 1920; 7:374-425.

7. Membrive NA, Kazuma FJ, Silveira TGV, Teixeira JJV, Reinhold-Castro KR, Teodoro U. Disseminated cutaneous leishmaniasis caused by Leishmania braziliensis in Southern Brazil. Rev Inst Med Trop Sao Paulo. 2017;59:e37.

8. Calvopina M, Gomez EA, Uezato H, Kato H, Nonaka S, Hashiguchi Y. Atypical clinical variants in New World cutaneous leishmaniasis: disseminated, erysipeloid, and recidiva cutis due to Leishmania (V.) panamensis. Am J Trop Med Hyg. 2005;73:281-4.

9. Vélez ID, Jiménez $A$, Vásquez $D$, Robledo SM. Disseminated Cutaneous Leishmaniasis in Colombia: Report of 27 Cases. Case Rep Dermatol. 2015 ;7:275-86.

10. World Health Organization. Control of the leishmaniasis: report of a meeting of the WHO Expert Committee on the Control of Leishmaniases, Geneva, 22-26 March 2010. WHO technical report series; n. 949. Geneva: World Health Organization; 2010.

11. Alborzi A, Pouladfar GR, Fakhar M, Motazedian MH, Hatam GR, Kadivar MR. Isolation of Leishmania tropica from a patient with visceral leishmaniasis and disseminated cutaneous leishmaniasis, southern Iran. Am J Trop Med Hyg. 2008;79:435-7.

12. Jones TC, Johnson WD Jr, Barretto AC, Lago E, Badaro R, Cerf B, et al. Epidemiology of American cutaneous leishmaniasis due to Leishmania braziliensis. J Infect Dis. 1987;156:73-83.

13. Guimarães LH, Queiroz A, Silva JA, Silva SC, Magalhães V, Lago EL, et al. Atypical Manifestations of Cutaneous Leishmaniasis in a Region Endemic for Leishmania braziliensis: Clinical, Immunological and Parasitological Aspects. PLoS Negl Trop Dis. 2016;10:e0005100.
14. Brasil. Ministério da Saúde. Secretaria de Vigilância em Saúde. Departamento de Vigilância das Doenças Transmissíveis. Manual de vigilância da leishmaniose tegumentar. Brasilia: Ministério da Saúde; 2017.

15. Queiroz A, Sousa R, Heine C, Cardoso M, Guimarães LH, Machado PR, et al. Association between an emerging disseminated form of leishmaniasis and Leishmania (Viannia) braziliensis strain polymorphisms. J Clin Microbiol. 2012;50:4028-34.

16. Leopoldo PT, Machado PR, Almeida RP, Schriefer A, Giudice A, de Jesus AR, et al. Differential effects of antigens from $L$. braziliensis isolates from disseminated and cutaneous leishmaniasis on in vitro cytokine production. BMC Infect Dis. 2006:6:75

17. Convit J, Pinardi ME, Rondón AJ. Diffuse cutaneous leishmaniasis: a disease due to an immunological defect of the host. Trans R Soc Trop Med Hyg. 1972:66:603-10.

18. Guerra JA, Coelho LI, Pereira FR, Siqueira AM, Ribeiro RL, Almeida TM, et al. American tegumentary leishmaniasis and HIV-AIDS association in a tertiary care center in the Brazilian Amazon. Am J Trop Med Hyg. 2011;85:524-7.

19. Calvopina M, Aguirre C, Cevallos W, Castillo A, Abbasi I, Warburg A. Coinfection of Leishmania guyanensis and Human Immunodeficiency Virus-Acquired Immune Deficiency Syndrome: Report of a Case of Disseminated Cutaneous Leishmaniasis in Ecuador. Am J Trop Med Hyg. 2017;96:1151-4.

20. Machado PR, Rosa ME, Costa D, Mignac M, Silva JS, Schriefer A, et al. Reappraisal of the immunopathogenesis of disseminated leishmaniasis: in situ and systemic immune response. Trans R Soc Trop Med Hyg. 2011 Aug;105(8):438-44.

21. Teixeira MJ, Teixeira CR, Andrade BB, Barral-Netto M, Barral A. Chemokines in host-parasite interactions in leishmaniasis. Trends Parasitol. 2006;22:32-40.

22. Machado PR, Rosa ME, Guimarães LH, Prates FV, Queiroz A, Schriefer A, et al. Treatment of Disseminated Leishmaniasis With Liposomal Amphotericin B. Clin Infect Dis. 2015;61:945-9.

23. Mendes DS, Dantas ML, Gomes JM, Santos WL, Silva AQ, Guimarães LH, et al. Inflammation in disseminated lesions: an analysis of CD4+, CD20+, CD68+, CD31+ and vW + cells in non-ulcerated lesions of disseminated leishmaniasis. Mem Inst Oswaldo Cruz. 2013;108:18-22.

24. Arana B, Rizzo N, Diaz A. Chemotherapy of cutaneous leishmaniasis: a review. Med Microbiol Immunol. 2001;190:93-5.

25. Minodier P. Parola P. Cutaneous leishmaniasis treatment. Travel Med Infect Dis 2007;5:150-8.

26. Wortmann G, Zapor M, Ressner R, Fraser S, Hartzell J, Pierson J, et al. Liposomal amphotericin B for treatment of cutaneous leishmaniasis. Am J Trop Med Hyg. 2010;83:1028-33 
27. Solomon M, Pavlotzky F, Barzilai A, Schwartz E. Liposomal amphotericin B in comparison to sodium stibogluconate for Leishmania braziliensis cutaneous leishmaniasis in travelers. J Am Acad Dermatol. 2013 Feb;68(2):284-9

28. Urbina JA. Lipid biosynthesis pathways as chemotherapeutic targetsin kinetoplastid parasites. Parasitology. 1997;114(Suppl):S91-9.

29. Sundar S, Jha TK, Thakur CP, Engel J, Sindermann H, Fischer C, et al. Oral miltefosine for Indian visceral leishmaniasis. N Engl J Med. 2002;347:1739-46.

30. Soto J, Toledo J, Gutierrez P, Nicholls RS, Padilla J, Engel J, et al. Treatment of american cutaneous leishmaniasis with miltefosine, an oral agent. Clin Infect Dis. 2001;33:E57-61.

31. Soto J, Rea J, Balderrama M, Toledo J, Soto P, Valda L, et al. Efficacy of miltefosine for Bolivian cutaneous leishmaniasis. Am J Trop Med Hyg. 2008;78:210-1.
32. Machado PR, Ampuero J, Guimarães LH, Villasboas L, Rocha AT, Schriefer A, et al. Miltefosine in the treatment of cutaneous leishmaniasis caused by Leishmania braziliensis in Brazil: a randomized and controlled trialPLoS Negl Trop Dis. 2010;4:e912.

33. Chrusciak-Talhari A, Dietze R, Chrusciak Talhari C, da Silva RM, Gadelha Yamashita EP, de Oliveira Penna G, et al. Randomized controlled clinical trial to access efficacy and safety of miltefosine in the treatment of cutaneous leishmaniasis Caused by Leishmania (Viannia) guyanensis in Manaus, Brazil. Am J Trop Med Hyg. 2011; 84(2):255-60.

34. González LM, Vélez ID. Miltefosine for disseminated cutaneous leishmaniasis. Biomedica. 2006;26(Suppl 1):13-6.

35. Hamzavi SS, Sanaei Dashti A, Kadivar MR, Pouladfar G, Pourabbas B. Successful treatment of disseminated cutaneous leishmaniasis with liposomal amphotericin B and miltefosine in an eight-year-old girl. Pediatr Infect Dis J. 2018;37:275-77.

Elaboration and writing of the manuscript

Elaboration and writing of the manuscript

How to cite this article: Machado GU, Prates FV, Machado PRL. Disseminated leishmaniasis: clinical, pathogenic and therapeutic aspects. An Bras Dermatol. 2019;94(1):09-16 


\section{QUESTIONS}

1. Leishmaniasis is included in the list of priority diseases by the World Health Organization and is characterized by:

a) Cosmopolitan distribution, mostly in the planet's northern hemisphere, affecting those in the lowest income group

b) Transmission by several species of sandflies, with Leishmania amazonensis as its main causative agent in Brazil

c) Intracellular parasitism, with defense mechanisms associated with Th2 response

d) Heterogeneous integumentary or visceral disease associated with ecological and socioeconomic issues

2. In relation to the differences between disseminated leishmaniasis (DL) and diffuse (anergic) cutaneous leishmaniasis (DCL), choose the correct alternative.

a) DCL is characterized by an exacerbated Th1 cellular immune response

b) Nodules and plaques infiltrated into various body segments are characteristic of DL

c) Montenegro test is characteristically negative in DCL

d) Nasal mucosal involvement occurs in about $53 \%$ of patients with DCL

3. Choose the INCORRECT alternative about the methods for diagnosis confirmation of disseminated leishmaniasis.

a) Montenegro test reveals adequate host cellular immune response, but may be negative even in the presence of active disease in most cases

b) Anatomopathological examination of the lesion reveals small amounts of amastigote parasites inside macrophages

c) Examination of lesion fragment with negative PCR for Leishmania does not rule out the diagnosis of disseminated leishmaniasis

d) Intense perifollicular inflammation may occur in papular lesions, with a predominance of macrophages and $\mathrm{T}$ and $\mathrm{B}$ lymphocytes
4. With regard to disseminated leishmaniasis, we can affirm:

a) It is a very rare disease that occurs mainly in the northern region of Brazil and is mainly caused by L. (Viannia) braziliensis

b) Most of the time it is associated with several types of immunosuppression, mainly including HIV infection

c) The main causative agent in Brazil is L. (Viannia) braziliensis, but other species of Leishmania may be associated, even in the absence of comorbidities or immunosuppression

d) Its clinical picture is very similar to that of diffuse leishmaniasis, but the nodular infiltrative lesions rich in parasites allow the diagnosis of the disseminated form

\section{Histopathological examination of disseminated leish-} maniasis

a) Reveals dense granuloma formation and a few amastigote forms

b)May reveal vasculitis and necrosis in papular lesions

c) Reveals infiltrate with many macrophages and a few $\mathrm{T}$ and B cells

d)Reveals large numbers of plasma cells and neutrophils in the ulcerated lesions

6. The occurrence of a large number of DL cases in the endemic region for $L$. (V.) braziliensis

a) Is associated with a greater number of individuals with immunosuppression caused by HIV or other agents

b)May be due to changes in the genome of L. (V.) braziliensis and to several factors not yet elucidated

c) Is related to the untimely use of pesticides in agriculture by young adult males and to a habit change of the vectors

d) May be due to familial genetic changes that increase the predisposition to the disease 
7. Regarding the pathogenesis of disseminated leishmaniasis, we can highlight:

a) The cellular immune response is diminished in the peripheral blood and lesions, facilitating the dissemination of the parasite

b)After inoculation of the promastigote forms, neutrophils and macrophages are the first to phagocyte the parasite. At this time, the local production of IL-12 and TNF favors an inadequate inflammatory response, facilitating dissemination

c) The high number of parasites in the tissue reflects the low production of Th1 cytokines

d)Despite the lower Th1 production in the peripheral blood, cellular immunity response is conserved in situ, which may explain the low amount of parasites in the lesions and the progression to ulceration

\section{With regard to the definition and clinical picture of $\mathrm{DL}$, we can affirm:}

a) Many patients present with dissemination after a few weeks of the initial ulcer, with symptoms of fever, asthenia, chills, and others

b)DL is defined by the presence of at least 10 lesions on any area of the skin

c) Nasal mucosal involvement is uncommon, but cases are intense and severe

d)Infiltrated and nodular lesions predominate mainly in the lower limbs

9. The differentiation between classic DL and cutaneous leishmaniasis with multiple lesions in immunosuppressed patients is mainly due to the fact that:

a) DL occurs only in endemic areas for $L$. (V.) braziliensis

b) In cutaneous leishmaniasis in the immunosuppressed, no mucosal lesion is observed and the parasite load is large

c) Response to treatment of DL is rapid in most cases, unlike in immunosuppressed patients

d) In immunosuppressed patients, no symptoms of dissemination are observed, the lesions are atypical, and many amastigote forms are found in the cell infiltrate
10. Disseminated leishmaniasis is considered a serious and emerging disease. Mark the only correct alternative in relation to its treatment.

a) The parenteral use of glucantime at the maximum dose recommended for 30 days shows a cure rate above $50 \%$

b) In the occurrence of mucosal lesions, the first treatment option should be amphotericin B even in elderly patients or patients with kidney disease

c) Oral therapy with Miltefosine induces healing in more than $70 \%$ of patients

d) Liposomal amphotericin B shows a high cure rate mainly at doses above $35 \mathrm{mg} / \mathrm{kg}$
Answers

Epstein barr virus and skin. An Bras Dermatol. 2018;93(6):786-99.

\begin{tabular}{llll}
\hline $1-\mathrm{A}$ & $4-\mathrm{D}$ & $7-\mathrm{C}$ & $10-\mathrm{D}$ \\
$2-\mathrm{D}$ & $5-\mathrm{C}$ & $8-\mathrm{D}$ & \\
$3-\mathrm{C}$ & $6-\mathrm{B}$ & $9-\mathrm{D}$ &
\end{tabular}

Papers

Information for all members: The EMC-D questionnaire

is now available at the homepage of the Brazilian Annals

of Dermatology: www.anaisdedermatologia.org.br. The

deadline for completing the questionnaire is 30 days from

the date of online publication. 